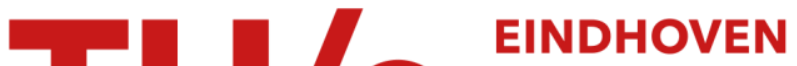

\section{Methods for estimation of the vacuum status in vacuum circuit breakers}

Citation for published version (APA):

Merck, W. F. H., Damstra, G. C., Bouwmeester, C. E., \& Gruntjes, R. J. B. (1999). Methods for estimation of the vacuum status in vacuum circuit breakers. IEEE Transactions on Dielectrics and Electrical Insulation, 64, 400404. https://doi.org/10.1109/94.788733

DOI:

10.1109/94.788733

Document status and date:

Published: 01/01/1999

\section{Document Version:}

Publisher's PDF, also known as Version of Record (includes final page, issue and volume numbers)

\section{Please check the document version of this publication:}

- A submitted manuscript is the version of the article upon submission and before peer-review. There can be important differences between the submitted version and the official published version of record. People interested in the research are advised to contact the author for the final version of the publication, or visit the $\mathrm{DOI}$ to the publisher's website.

- The final author version and the galley proof are versions of the publication after peer review.

- The final published version features the final layout of the paper including the volume, issue and page numbers.

Link to publication

\section{General rights}

Copyright and moral rights for the publications made accessible in the public portal are retained by the authors and/or other copyright owners and it is a condition of accessing publications that users recognise and abide by the legal requirements associated with these rights.

- Users may download and print one copy of any publication from the public portal for the purpose of private study or research.

- You may not further distribute the material or use it for any profit-making activity or commercial gain

- You may freely distribute the URL identifying the publication in the public portal.

If the publication is distributed under the terms of Article 25fa of the Dutch Copyright Act, indicated by the "Taverne" license above, please follow below link for the End User Agreement:

www.tue.nl/taverne

Take down policy

If you believe that this document breaches copyright please contact us at:

openaccess@tue.nl

providing details and we will investigate your claim. 


\title{
Methods for Estimation of the Vacuum Status in Vacuum Circuit Breakers
}

\author{
W. F. H. Merck, G. C. Damstra \\ Eindhoven University of Technology, Eindhoven \\ C. E. Bouwmeester \\ Holec Middenspanning B.V., Hengelo \\ and R. J. B. Gruntjes \\ KEMA HV Laboratory, Arnhem, The Netherlands
}

\begin{abstract}
In this paper several methods are described for the estimation of the pressure inside vacuum interrupters which have been in operation during many years. The methods are applicable without demounting the interrupters and use only electrical measuring techniques. According to these methods the vacuum circuit breakers are subjected to synthetic circuits, switch-off limited currents, either $10 \mathrm{~A}$ dc or $300 \mathrm{~A}$ ac. With the $10 \mathrm{~A}$ dc method the height of arc voltage spikes are measured and represented in a histogram. The shape of the histogram is discriminative for pressures below or above $10^{-2} \mathrm{~Pa}$. Switching tests with currents of 200 to $400 \mathrm{~A}$ ac in inductive and capacitive circuits also showed different behavior for internal pressures below or above $10^{-1} \mathrm{~Pa}$. A three phase $200 \mathrm{~A}$ test device with a $10 \mathrm{kV}$ recovery voltage, fed from a standard 380 V supply, showed similar results.
\end{abstract}

\section{INTRODUCTION}

$\mathrm{V}$ ACUUM circuit breakers have operated successfully in medium voltage distribution networks for more than 25 years and their application is still increasing. Nowadays we notice that network owners start to worry about the vacuum condition and consequently about the switching capabilities of these vacuum circuit breaker (VCB) and want to have a simple, accurate, unambiguously discriminative method to check the vacuum condition of the VCB in service.

In order to determine the internal pressure of vacuum tubes just after production, most manufacturers use the Penning or magnetron method. However, during service the internal pressure might increase for some unknown reasons. Network owners may deem it necessary to recheck the pressure within the vacuum tubes as a standard maintenance procedure, in order to ensure that they are still able to perform correctly when short circuit currents have to be interrupted. For VCB rated at $12 \mathrm{kV}$, the contact distance is $\approx 0.01 \mathrm{~m}$. Considering the Paschen curve for this contact distance [1] it is found that the pressure of $10^{-2} \mathrm{~Pa}$ is still in the left $\mathrm{HV}$ branch with an ignition voltage $>40 \mathrm{kV}$. That is why this pressure is generally considered to be sufficient for good performance. Above a pressure of $\approx 0.1$ to $1 \mathrm{~Pa}$ the ignition voltage decreases dramatically. Bos [1] investigated 63 papers and patents finding some 25 different methods for in situ measurement of the internal pressure of vacuum circuit breakers: Methods based on Penning and magnetron effects [2-4] are considered impractical; $\mathrm{dc}$ field emission [5] is applicable above $0.01 \mathrm{~Pa}$ only; discharge noise detection $[6,7]$ is applicable from $2 \times 10^{-3} \mathrm{~Pa}$ on; high frequency pre-discharge current measurement $[6,7]$ is not unambiguous; high frequency emission currents show too much scatter $[6,7]$; dc chopping current measurement $[8,9]$ is insufficiently discriminative; $\mathrm{dc}$ arc life time $[8,9]$ is not discriminative under $1 \mathrm{~Pa}$; ignition voltage tests $[5-7,9]$ indicate pressures above $1 \mathrm{~Pa}$ only and arc voltage measurement $[5,8,10]$ is indicative above $50 \mathrm{~Pa}$. In short: none of those methods was considered to be practical and unambiguously discriminative for application on site.

The aim of this paper is to investigate new methods that are discriminative, reliable and applicable in service. The following physical effects have been investigated [11,12]:

1. The behavior of the arc voltage $\left(V_{\text {arc }}\right)$ of a low current $\mathrm{dc} \operatorname{arc}(10 \mathrm{~A})$. The basic idea is that the low current arc generates only one cathode spot $[13,14]$ and has to be re-ignited whenever a new cathode spot has to be formed. This produces a sudden increase in arc voltage. The presence of gas molecules in the volume which earlier might have been desorbed from the contact surfaces will facilitate the re-ignition of the arc at a new cathode spot. The more gas molecules are available, the lower the reignition arc voltage spike will be and the lower will be the mean arc voltage. On the other hand, the number of voltage spikes above a certain value, say $30 \mathrm{~V}$, will increase with decreasing pressure $[11,15]$.

2. Re-ignition after interruption of inductive and capacitive currents of 200 to $400 \mathrm{~A}[12,16]$

3. Re-ignition of a three phase $200 \mathrm{~A}$ current with transient recovery voltage 
(TRV) of 10 to $20 \mathrm{kV}$ was developed. Also here re-ignition of the arc is expected to be a measure of the vacuum condition $[12,16]$.

In the following Sections, the test circuits will be described and the measuring results will be given.

\section{ARC VOLTAGE MEASUREMENTS}

The scheme of the test circuit is presented in Figure 1. The leads, connecting the test circuit to the $380 \mathrm{~V}$ busbar, contain capacitors $\mathrm{C}_{\mathrm{m}}$ $(100 \mu \mathrm{F})$ for limiting the $\mathrm{dc}$ current to $9.7 \mathrm{~A}$ and inductors $\mathrm{L}_{\mathrm{m}}(3.7 \mathrm{mH})$ for protecting the rectifier diodes from inrush currents. $C_{1}$ and $C_{2}$ $(100 \mu \mathrm{F})$ are the smoothing capacitors of the three-phase rectifier bridge whereas capacitors $\mathrm{C}_{3}$ and $\mathrm{C}_{4}(20 \mathrm{nF})$ reduce the TRV on the VCB. Coils $\mathrm{L}_{1}$ and $L_{2}(90 \mathrm{mH})$ serve for the continuation of the direct current through the $V C B$, fed by the induced voltage $\rightarrow L d i / d t$. Therefore, the resonance frequency of the TRV is $3.6 \mathrm{kHz}$, yielding $d V_{T R V} / d t=1 \mathrm{kV} / \mu \mathrm{s}$. The direct current source voltage is $V_{A B}=620 \mathrm{~V}$, and the dc current is measured with a Hall-probe current transducer (CT). It should be noticed that the circuit is symmetrical to the neutral line $N$. The vacuum breaker used has copper-chromium contacts $(\mathrm{CuCr} 75 / 25)$ with a diameter of $40 \mathrm{~mm}$ and a contact gap of $10 \mathrm{~mm}$.

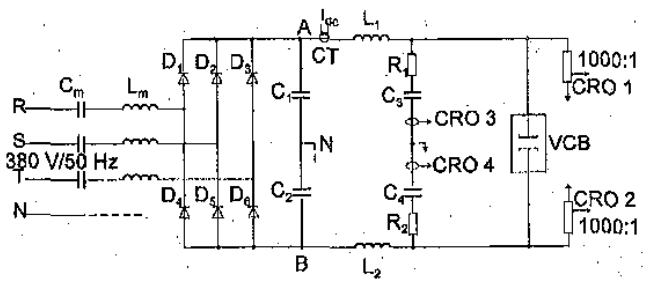

Figure 1. Scheme of the test circuit for investigation of the arc voltage of dc currents in the range of $10 \mathrm{~A}$. Component values are given in the text.

In order to measure the voltage spikes accurately, a sampling time of $50 \mathrm{~ns}$ was chosen $\left(f_{s}=20 \mathrm{MHz}\right)$. The vacuum chamber of the VCB is connected to a Balzers vacuum pump system, containing a turbomolecular pump and needle valve for filling the interrupter with atmospheric air in the range of $10^{-5}$ to $1 \mathrm{~Pa}$. The pressure was measured with a Penning ionization gauge. The arc voltage was analyzed during $2 \mathrm{~ms}$. The $\mathrm{dc}$ current continues to flow during $\sim 400 \mathrm{~ms}$ after opening of the $\mathrm{VCB}$. The following time window was chosen: $2 \mathrm{~ms}$, starting $30 \mathrm{~ms}$ after initiation of the arc. The results of these measurements are reported in the next section.

From Figure 1 we see that the anode and cathode voltages to neutral are measured separately. The internal shield of the VCB is at a floating potential. The anode and cathode voltages show the same shape and are subtracted, resulting in the arc voltage of Figure 2. It is clearly seen that $>100 \mathrm{~V}$ voltage spikes often appear. These high peaks are necessary to put extra energy in the re-ignition process of the cathode spot in order to keep the current flowing.

As a result of these HV peaks, currents with a frequency of $650 \mathrm{kHz}$ are introduced in the loop VСв- $\mathrm{C}_{3}-\mathrm{C}_{4}$, causing overshoots in the arc voltage which occasionally lead to $V_{\text {arc }}=0$ as is seen in Figure 2. The damping resistors $R_{1}$ respectively $R_{2}(90 \Omega)$ are introduced for adequate aperiodic damping of these currents. Due to the damping resistors, the arc voltage between spikes is stable at $\sim 20 \mathrm{~V}$.



Figure 2. Arc voltage resulting from subtraction of anode and cathode voltage, measured before introduction of the damping resistors $R_{1}$ and $R_{2}$.

\subsection{MEAN ARC VOLTAGE}

The arc voltage has been analyzed according to two different routines. First the mean arc voltage was determined during the $2 \mathrm{~ms}$ window and second the arc voltage peaks $>30$ V were counted and shown in histograms. It was found that the arcing time increases from $\sim 275 \mathrm{~ms}$ at $10^{-5} \mathrm{~Pa}$ to $1145 \mathrm{~ms}$ for $1 \mathrm{~Pa}$ with a very large scatter. The arcing time itself is not discriminative for the pressure.

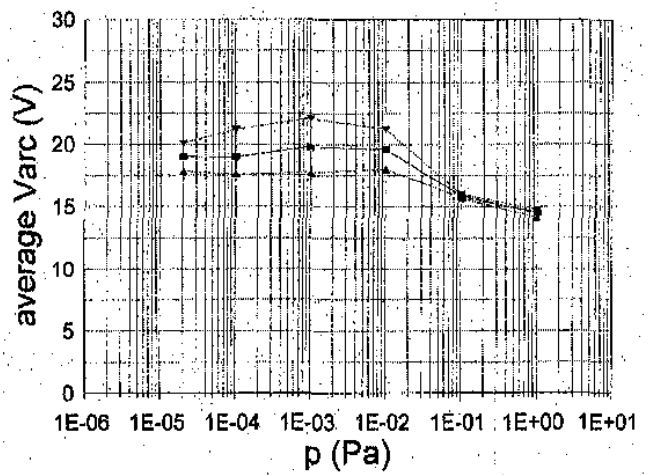

Figure 3. Mean value of arc voltage as a function of pressure $(\square)$ with indication of the scatter ( $\boldsymbol{\Lambda}$ and $\mathbf{\nabla}$ ), measured during 2, $30 \mathrm{~ms}$ after arc initiation.

The measurements starting at $30 \mathrm{~ms}$ after contact separation during a $2 \mathrm{~ms}$ time window result in a mean arc voltage shown in Figure 3 . The time window 30 to $32 \mathrm{~ms}$ is chosen to be sure that the contacts are in the end position $(5 \mathrm{~ms})$. The mean arc voltage for pressures from $10^{-5}$ to $10^{-2} \mathrm{~Pa}$ is nearly constant at a level of $19 \pm 2.5 \mathrm{~V}$ whereas there is a clear tendency of a smaller mean arc voltage for pressures $>10^{-2} \mathrm{~Pa}$. Also the scatter is much smaller. On the other hand it should be kept in mind that the mean arc voltage in the pressure interval from 100 to $10^{5} \mathrm{~Pa}$ increases from 20 to $70 \mathrm{~V}$ [9], which means that a mean arc voltage of $20 \mathrm{~V}$ is not unambiguously indicative of a very low pressure. At high pressure however voltage spikes occur less frequently and are much smaller, which is seen on the histograms of voltage spikes (Figure 4). 

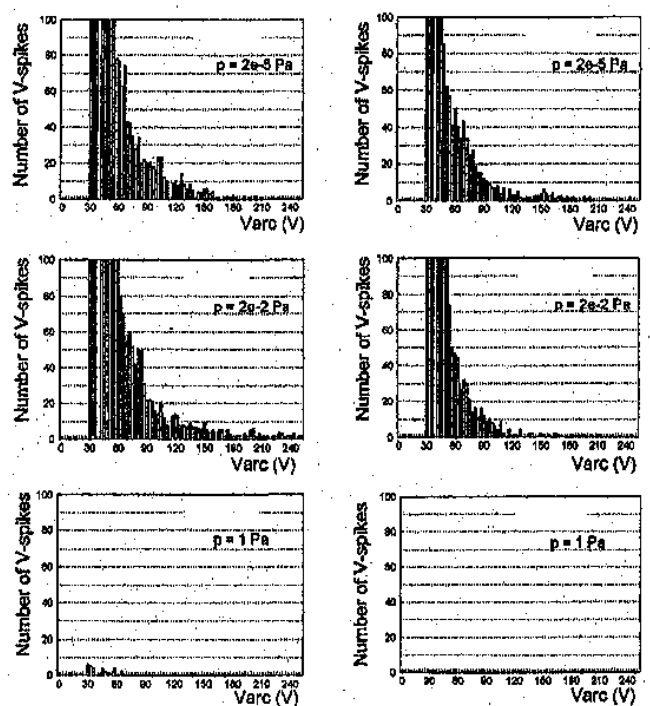

Figure 4. Histograms of arc voltage spikes $>30 \mathrm{~V}$, measured during 2, $30 \mathrm{~ms}$ after initiation of the arc for $10^{-5} \mathrm{~Pa}$ (top); $10^{-2} \mathrm{~Pa}$ (center) and $1 \mathrm{~Pa}$ (bottom).

\subsection{ARC VOLTAGE SPIKES}

From Figure 2 it is noticed that arc voltage peaks of $\sim 200 \mathrm{~V}$ appear. From the arc voltage recordings, histograms have been derived classifying the voltage spikes, according to their peak value, namely from 30 to $300 \mathrm{~V}$, with an interval of $3 \mathrm{~V}$. The results are presented in Figure 4. For every pressure value, four measurements were performed. Figure 4 shows two of them for pressure values of $2 \times 10^{-5}$ (top), $10^{-2}$ (center) and $1 \mathrm{~Pa}$ (bottom), respectively. It should be noted that there is little difference between the histograms for $2 \times 10^{-5}$ and $10^{-2} \mathrm{~Pa}$, whereas the histograms for $1 \mathrm{~Pa}$ are very different. At $10^{-1} \mathrm{~Pa}$ spikes of $50 \mathrm{~V}$ and higher have hardly been found [11]. A further analysis of the voltage spikes has been made by approximating the envelopes of the histograms by an exponential curve with a least squares method

$$
n=N \exp \left[-\frac{V_{\text {arc }}}{b}\right]
$$

For low pressure $\left(10^{-5}\right.$ to $\left.10^{-2} \mathrm{~Pa}\right)$ we find $N=750$ and $b=$ $25 \mathrm{~V}$ and at high pressure $\left(>10^{-1} \mathrm{~Pa}\right.$ ) we find $N=36$ and $b=$ $16.6 \mathrm{~V}$. This means that by comparison of these constants we can unambiguously distinguish between pressures above or below the critical pressure of $10^{-4} \mathrm{~Pa}$.

\section{INDUCTIVE CURRENT SWITCHING}

From the results obtained with the dc current method it might be expected that higher currents could give a better discrimination in combination with higher recovery voltages. In order to investigate this idea, an inductive current circuit fed by capacitors has been applied. The principle of such a circuit already has been used for current chopping measurements on MV switchgear [17]. The test circuit (Figure 5) consists of a capacitor $\left(C_{h}\right)$ of $110 \mathrm{~F}$, to be charged at $15 \mathrm{kV}$ and an inductance $\left(L_{h}\right)$ of $90 \mathrm{mH}$ tuned to a $50 \mathrm{~Hz}$ discharge current of $400 \mathrm{~A}$.

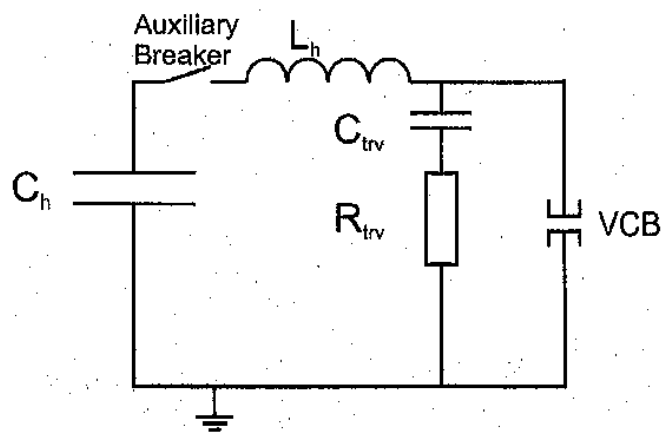

Figure 5. Test circuit for inductive current switching. Component values are given in the text.

In this circuit, after an arcing time of $9 \mathrm{~ms}$, the test breaker interrupts the current normally at the first current zero. The frequency of the recovery voltage is $\sim 12 \mathrm{kHz}$ determined by the capacitor $\left(C_{t r v}=2 \mathrm{nF}\right)$ parallel to the test breaker. The resistor $R_{t r v}(1000 \Omega)$ determines the height and damping of the TRV. The peak of the TRV is $24 \mathrm{kV}$. The pressure in the vacuum chamber was set in steps of $0.1 \mathrm{~Pa}$ from $1 \mathrm{~Pa}$ downwards. The critical pressure for re-ignition proved to be $0.3 \mathrm{~Pa}$.

\section{CAPACITIVE CURRENT SWITCHING}

Another storage capacitor test scheme provides a capacitive current switching condition [18]. Two capacitors $\mathrm{C}_{1}$ and $\mathrm{C}_{2}$ (each $55 \mu \mathrm{F}$ ) are connected to a common inductance $\mathrm{L}(90 \mathrm{mH})$ giving a resonance frequency of $50 \mathrm{~Hz}$ (Figure 6).



Figure 6. Test circuit for capacitive current switching. Component values are given in the text.

The test VCB interrupts the current through $\mathrm{C}_{2}$ at current zero. The rest of the circuit continues to oscillate at the higher frequency of $70 \mathrm{~Hz}$ [12]. The test object experiences a recovery voltage of the shape '1-cos' similar to the TRV after interruption of a capacitive current in an ac network. This situation is quite common in networks with floating neutral line, when a circuit breaker interrupts a fault current on an outgoing line or cable. The last pole to clear has to interrupt the capacitive ground fault current of that network. These currents mostly range from 30 to $300 \mathrm{~A}$. If one of the VCB poles has a bad vacuum, this situation may lead to multiple restrikes on that pole and to serious damage. A series of experiments has been performed with this capacitive circuit. The critical pressure for re-ignitions appears to be $0.2 \mathrm{~Pa}$. In Figure 7 and 8 oscillograms without and with re-ignition are given. 




Figure 7. Voltage $V_{\mathrm{VCB}}$ across and current $I_{\mathrm{VCB}}$ through the contacts of a vacuum circuit breaker in the capacitive current switching scheme at a pressure $<0.2 \mathrm{~Pa}$. No re-ignitions were found.



Figure 8. Voltage $V_{\mathrm{YCB}}$ across and current $I_{\mathrm{VCB}}$ through the contacts of a vacuum circuit breaker in the capacitive current switching scheme at a pressure $>0.2 \mathrm{~Pa}$. Five re-ignitions in the high frequency current can be observed.

\section{THREE PHASE TEST CIRCUIT}

Although the previously mentioned inductive and capacitive test circuits have improved the detection limit to $0.2 \mathrm{~Pa}$, the circuits are less practical due to the high weight of the storage capacitors. Another disadvantage is that for a three phase circuit breaker the test has to be repeated three times. For these reasons we have investigated a three phase circuit, directly fed from the $380 \mathrm{~V}$ busbar (Figure 9, [17]).

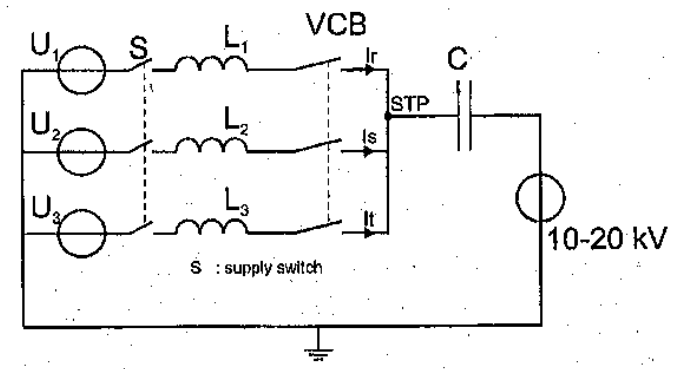

Figure 9. Three phase test circuit with synthetic TRV from loaded HV capacitor $\mathrm{C}$. Component values are given in the text.

The current is limited to $250 \mathrm{~A}$ by the inductances $\mathrm{L}_{1}, \mathrm{~L}_{2}$ and $\mathrm{L}_{3}$ $(3.7 \mathrm{mH})$. The star point of the three VCB poles is connected to a 10 or $20 \mathrm{kV}$ voltage transformer with a series capacitor $\mathrm{C}(3.3 \mathrm{nF}, 90 \mathrm{kV} \mathrm{dc})$, giving a typical ' $1-\cos ^{\prime}$ recovery voltage equivalent to the interruption of an applied capacitive current. Figure 10 shows typical oscillograms of a test where the pole in the $T$-phase has a vacuum pressure of $0.2 \mathrm{~Pa}$ and cannot withstand the recovery voltage. This appears from the fact that a spike is visible on the $T$-phase voltage $\left(U_{T}\right)$ at the moment of collapse of the star point voltage $\left(U_{S T P}\right)$. The $T$-phase contained the VCB with controllable pressure from $10^{-5}$ to $1 \mathrm{~Pa}$. During the re-ignition the $T$-phase conducts the discharge current of capacitor $C$ which causes an induced voltage $-\mathrm{L}_{3} d i / d t$ which is visible as the small voltage spike. Below a pressure of $0.2 \mathrm{~Pa}$ no re-ignitions were found.

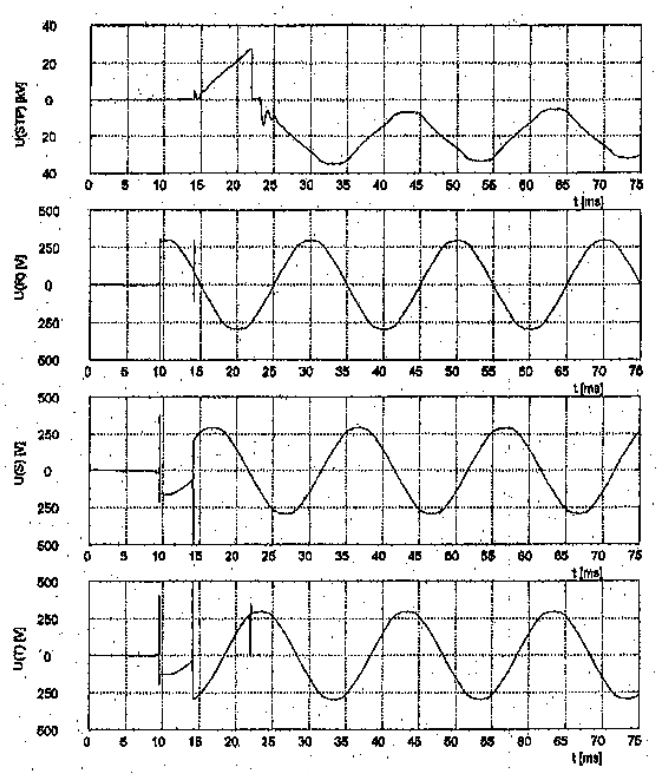

Figure 10. Star point voltage $U_{S T P}$ and phase voltages $U_{R}, U_{S}$ and $U_{T}$ where a re-ignition occurs at $t=22 \mathrm{~ms}$ in the $T$-phase VCB which has a pressure $>0.2 \mathrm{~Pa}$.

\section{STANDARD TYPE TESTS}

In practice the condition of $\mathrm{VCB}$ is often checked by imposing a $20 \mathrm{kV}_{\mathrm{rms}}$ voltage upon the open contacts during 1 min. It means that during the test, the peak value of the test voltage is $28 \mathrm{kV}$ which is far below the ignition voltage of $40 \mathrm{kV}$ found in the Paschen curve [1] for pressures $<10^{-1} \mathrm{~Pa}$. When no discharge is observed, the VCB is considered to have a vacuum condition sufficiently good for operation. For comparison, this type test was also carried out with a constant test voltage of $20 \mathrm{kV}_{\mathrm{rms}}$ and varying pressure in the vacuum chamber. It turned out that no discharges were observed until the pressure exceeded $2 \mathrm{~Pa}$ (see Figure 11) which means that in practice VCB will be accepted even if the pressure is above the critical value of $10^{-2} \mathrm{~Pa}$. It is also obvious that the methods for vacuum testing treated in this paper give better results than the one minute type test.

\section{CONCLUSIONS}

$\mathrm{F}$ OUR diagnostic methods for testing the vacuum condition were found that will perform better than the widely used standard type test applying a test voltage for $1 \mathrm{~min}$. From the measurements it is clear that the arc voltage analysis at low dc currents $(10 \mathrm{~A})$ is a useful method to obtain a good estimate for the internal pressure in a VCB, especially to distinguish whether the pressure is below or above the critical value of $10^{-2} \mathrm{~Pa}$. First of all, the mean arc voltage during a $2 \mathrm{~ms}$ interval $30 \mathrm{~ms}$ after the initiation of the arc gives a first indication of the gas pressure, 


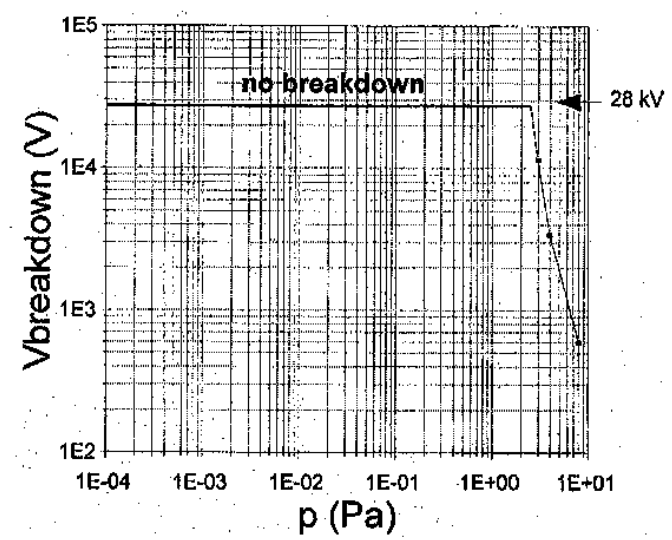

Figure 11. Breakdown performance of a $12 \mathrm{kV} \mathrm{VCB}$ at different pressures during $1 \mathrm{~min} 20 \mathrm{kV}$ test. Discharges are found above $2 \mathrm{~Pa}$ only; showing that this test is inadequate.

in order to distinguish between $10^{-2} \mathrm{~Pa}$ and a pressure $>100 \mathrm{~Pa}$. The number of arc voltage spikes $>30 \mathrm{~V}$ has to be determined additionally. The resulting histogram is well discriminative for pressures below and above the critical pressure. In order to improve the selectivity of this method, the availability of test curves of the VCB, recorded as a type test by the manufacturer would be of great value. The equipment needed for measurements in site can be mounted on a hand carriage and the analysis can be worked out automatically with a dedicated programs.

Inductive or capacitive current tests with 200 to $400 \mathrm{~A}$ indicate pressures $>0.2 \mathrm{~Pa}$, if re-ignitions occur. The storage capacitors to be used can be cumbersome for application on site.

A three phase test circuit with $200 \mathrm{~A}$ from a low voltage supply and recovery voltages of 10 to $20 \mathrm{kV}$ from a synthetic circuit also can indicate pressures $>0.2 \mathrm{~Pa}$ by re-ignition and is somewhat easier to apply in field tests.

Standard vacuum condition test methods, based on ac or dc test voltages, have a low-pressure detection limit of $1 \mathrm{~Pa}$. Test voltages above the permitted IEC values are not recommended in order to avoid overstress of the dielectric structures and other components near the circuit breaker. The vacuum diagnostic methods described in this paper are all obviously superior to the $1 \mathrm{~min}$ type test method. This test method should be dissuaded. The voltage spikes histograms method has proved to be superior to all methods investigated.

\section{ACKNOWLEDGMENT}

The authors like to thank J. Vossen, A. van Staalduinen and R. Kerkenaar for their technical support with the experiments.

\section{REFERENCES}

[1] P. J. Bos, "Measurement of the Pressure in a Vacuumtube", Rep. EG[96]807, Department Electrical Energy Systems, Eindhoven University of Technology, Eindhoven, pp. 1-57, 1996, (in Dutch).

[2] K. Kageyama, "Pulsed Series Discharges in Crossed Fields Generated in Vacuum Switches for Pressure-measurement Application", J. Vac, Sci, and Techn. A, Vol. 2, No. 4, pp. 1567-1575, 1984.

[3] V. A. Korotchenko, I. A. Milyukin and S. L. Karpov, "Measurement of the Pressure of Residual Gases in Sealed-off HV Vacuum Switches", Telecom, and Radio Eng,, Vol. 47 , Pt. 2, No. 5, pp. 157-159, 1992 .

[4] performance of the performance of the W. Kuhl and K. Wiehl, "Device for Measuring the Internal Pressure of Vacuum Interrupters", Siemens Review, Vol. 45, No. 2, pp. 87-89, 1978.

[5] T. Binz, K, Möller and K, Stegmüller, "Beprüfung des Innendrucks von VakuumLeistungsschaltern in der Schaltanlage", Vakuum-Technik, Vol. 36, No. 4, pp. 114117, 1987, (in German).

[6] F. R. Froneck, D. König and R. Heinemeyer, "Fundamentals of new Electrical Methods for Verifying the Internal Pressure of Vacuum Interrupters after Long-time Service", Proceedings XIVth ISDEIV, Santa Fe (USA), 17-20 Sept, 1990, pp. 680-684, 1990.

[7] F. R. Froneck, D. König and R. Heinemeyer, "Electrical Methods for Verifying Internal Pressure of Vacuum Interrupters after Long-time Service", IEEE Trans, on Electrical Insulation, Vol. 28, No. 4, pp. 700-705, 1993.

[8] S. Anders and B. Jüttner, "Influence of Residual Gases on Cathode Spot Behavior", IEEE Trans. on Plasma Science, Vol. 19, No. 5, pp. 705-712, 1991.

[9] G. C. Damstra, R, P. P. Smeets and H. B. F. Poulussen, "Pressure Estimation in Vacuum Circuit Breakers", IEEE trans. DEI, Vol, 2, No. 2, pp. 198-201, 1995.

[10] S. Anders, B. Jüttner and H. Pursch, "Verfahren zur Beurteilung des Innendrucks von Vakuumschaltkammern", Akademie der Wissenschaften, Berlin, Deutschiand, Deutsches Patentamt, Patentschrift DD 297034 A5, 1991.

[11] R. J. B. Gruntjes, "Determination of the Vacuum Quality in Vacuum Circuit Breakers", M. Sc-thesis, EG[96]838, Eindhoven University of Technology, pp. 1-63, 1996, (in Dutch).

[12] C. E. Bouwmeester, Synthetic Test Circuits for MV Switchgear Development, especially for Vacuum Circuit Breakers, M. Sc thesis, EG[97]863, Eindhoven University of Technology, pp. 1-62, 1997, (in Dutch).

[13] J. E. Daalder, "Distributions of Spotdiameter for Single- and Multi-cathode Cathode Discharges in Vacuum", EUT report 73-E-32, Fac. of Electr. Eng., Eindhoven, pp. 126, 1973 .

[14] J. E. Daalder, Cathode Erosion of Metal Vapor Arcs in Vacuum, $\mathrm{PhD}$ thesis, Eindhoven University of Technology, Eindhoven, pp. 1-158, 1978.

[15] W. F. H. Merck, G. C. Damstra and R. J. B. Gruntjes, "Estimation of Vacuum Condition in Vacuum Circuit Breakers", ISDEIV 18th, Eindhoven, Vol. 2, pp. 506-509, 1998.

[16] G. C. Damstra, W. F. H. Merck, P.J. Bos and C. E. Bouwmeester, "Diagnostic Methods for Vacuum State Estimation", ISDEIV 18th, Eindhoven, Vol. 2, pp. 443-446, 1998.

[17] G. C. Damstra, "Current Chopping and Overvoltages in Relation to System Parameters", CIGRE, Report 120, pp. 1-11, 1964.

[18] G. C. Damstra, "Reflections on Capacitive Switching Tests", CIGRE SC 13, Colloquium Florianapolis, paper 1-13, pp. 1-11, 1995.

This paper is based on a presentation given at the 18th International Symposium on Discharges and Electrical Insulation in Vacuum, Eindhoven, The Netherlands, 17-21 August 1998.

Manuscript was received on 4 May 1998. 